\title{
Expectations and experiences of tourists on attractions in Batangas Province
}

Apritado, Jennie Margaret $\triangle \triangle$

Lyceum of the Philippines University-Batangas, Philippines (jen_mar_143@yahoo.com.ph)

Borbon, Noelah Mae D.

Lyceum of the Philippines University-Batangas, Philippines (nmdborbon@lpubatangas.edu.ph)

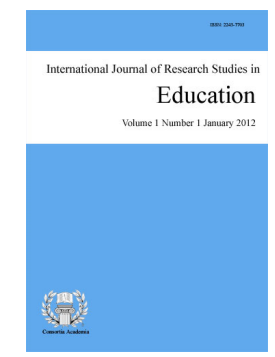

ISSN: 2243-7703 Online ISSN: 2243-7711

OPEN ACCESS

\section{Abstract}

This research assessed the experiences and expectations of tourists on attractions in Batangas province. The result reveals the expectations and experiences on attractions in terms of environment, atmosphere, transportation, tourism service and tourism; tested the significant relationship between tourists' expectations and experiences on attractions in Batangas Province; and proposed an action plan for innovative improvement of Batangas province' tourist destination. The study used descriptive research method and a modified questionnaire. The participants of the study were taken from the attractions. Data were gathered and presented using different statistical tools. The study concluded that: the expectations and experiences are parallel in all given instances on pleasantly-built environment, friendliness of the local people, various types of local transport, personal safety and security and opportunity to participate in religious activities. Moreover, there is a significant relationship between expectations and experiences on attractions in Batangas province. There is high satisfaction in the aspect of atmosphere in the attractions. Furthermore, this study provides recommendation to improve the management of attractions on the development of new facilities and improvement on the existing tourist activities, invest to develop or acquire new facilities in providing new trends tourist activities. The management of attraction may utilize the proposed action plan for innovative improvement.

Keywords: expectations; experiences; attractions; Batangas Province 


\section{Expectations and experiences of tourists on attractions in Batangas Province}

\section{Introduction}

Tourism is a dynamic and competitive industry that requires to adjust continuously to customers' changing needs and desires. As described similarly by Tourism Education (2016), the industry is growing speedily with emergence of new challenges and opportunities based on the market demand. There would be employment opportunities, consumption on supply of good and services, establish linkages/partnerships, and the likes that will create a greater impact in economic growth. The market value of tourism products and services may constitute economic growth, leading to further development within sectors. The tourism industry offers a wide range of services in eight different sectors or areas: accommodation, attractions, adventure tourism and recreation, food and beverage, transportation, events and conferences, travel trade, and tourism service (Canadian Human Resource Council, n.d.).

This study focused on attractions in Batangas Province, Philippines. People travel for a variety of reasons: to escape, explore, understand, and participate. Attraction is the key feature of all tourism products (Stange \& Brown, 2010). The context of attractions creates the opportunity to have a meaningful experience or may give a bigger expectation among travelers. Environment, atmosphere, transportation, tourism services, and activities maximize or elaborate the positive impact on the attractions' survival. These are important factors in tourists' decision (Becken \& Scott, 2010). The success of attractions rests mainly on the high level of satisfaction and notable experiences of tourists. Thus, it can stimulate even greater interest or motivation among tourism management to ensure service quality and infrastructure improvement.

Batangas is described as eco-friendly destination with its natural attractions; may witness the admirable seascape, inland water, and the majestic Taal Volcano lying at the center of the lake. Moreover, the province is rich in culture, heritage and historical evidences. Batangas Province is embraced by natural, cultural and heritage attractions. Tourists have the highest expectation of better value in a significant way as they visit places. However, the gap between the expectations and experiences will perceive as underperforming against the experience (Kucharsky, 2015), while meeting the expectation reflects customer satisfaction (Smith, 2012).

Many people fantasize about visiting the most renowned attractions but the reality during the visit may not always live up to holidaymakers' expectations. The website or brochures show the attractions as tourists might imagine them to be, followed by what they are like in real life (Coffey, 2017). Unfortunately, a holiday with high expectations ended up being severely disappointing as the travelers rated their actual experiences. Satisfaction is determined by how well their actual experience matches their pre-conceived expectations. The overall satisfaction is determined by whether travelers' experiences exceed expectations related to quality and variety of goods/services and destination accessibility (Wang, 2016).

This research revealed the current situation of attractions based on the tourists' assessments. Thus, the results were the mainstream of tourist destination management to do tourism planning. Tourism and hospitality students will develop a critical awareness of how tourism can be enhanced and protected. On the other hand, it also helps the tourism and hospitality educators identify ways sustainable tourism can be introduced to students. The academe, being one of these people-oriented industries, will raise broader understanding by creating awareness of what should be involved in undertaking innovative improvements of the tourist destinations, specifically in Batangas province. Furthermore, the researcher believes that attractions must be innovative. Being innovative has a great impact on tourist arrival, customers' preference, decision-making, and opening a new prospect to Batangas province's tourist destinations. 


\subsection{Objectives of the study}

This research study mainly assessed the experiences and expectations of tourists on attractions in Batangas province. Specifically, this study 1) presented the profile of attractions in terms of frequency of visits; 2) assessed the expectations and experiences on attractions in terms of environment, atmosphere, transportation, tourism service and tourism activities; 3) tested the significant relationship between tourists' expectations and experiences on attractions in Batangas Province; 4) proposed an action plan for innovative improvement of Batangas province's tourist destination.

\section{Methodology}

Descriptive research was used to obtain the information relating to or describing the relationship between variables or conditions substantial in assessing attraction and resort. The method used will help to furtherly explain the significant relationship between the perceived variables of tourists' expectation-experience. Analogous to collecting data to test hypotheses or to answer questions, find out how things are, or how they have been (Rodrigo, 2012).

The participants of the study were taken from the identified attractions. These are the top 8 tourist destinations in the province of Batangas based on the number of tourist arrival in 2015 as released by the DOT. The computed number of respondents was generated proportionately from the total quantity of tourists who visited the attraction. There were a total of 280 tourists/participants. Respondents were chosen proportionately random sampling using the G- Power. All data were presented using the SPSS software. This study used a scale to measure and interprets the result of data gathered. The numerical value has equivalent verbal interpretation: 4 - Strongly Agree, 3 -Agree, 2 - Disagree, and 1- Strongly Disagree.

The instrument used variables based on the study of Quach (2013). The experts validated the modified questionnaire. It consists of two parts. Part I dealt with the respondents' profile in terms of frequency of visits; while, Part II assesses the tourists' feedback on attractions based on their expectations and experiences in terms of environment, atmosphere, transportation, tourism service, and tourism activities. After retrieving the questionnaire, data were tallied and interpreted using different statistical tools such as frequency distribution and weighted mean. The above-mentioned tools were used based on the objectives of the study. Frequency distribution identified the number of responses in each statement laid in the questionnaire. Weighted mean was used to answer respondents' feedback in visiting tourist attractions in Batangas Province based on their expectations and experiences. Simultaneously, Pearson $r$ was used to determine if there is a significant relationship between tourists' expectations and experiences in visiting the tourist attractions in Batangas.

\section{Result and discussion}

\section{Table 1}

Distribution of respondents according to profile $(N=280)$

\begin{tabular}{lccc}
\hline \multicolumn{1}{c}{ Attractions/Frequency of visits } & Frequency & Percentage & Rank \\
\hline Second Visit & 158 & 56.4 & 1 \\
Third Visit & 49 & 17.5 & 2 \\
Fourth Visit & 31 & 11.1 & 3 \\
Fifth or more & 42 & 15.0 & 4 \\
\hline
\end{tabular}

Table 1 indicates the respondents' profile in relation to the frequency of visits to the tourist attractions. On attractions, most of the respondents had their returned visit twice in the place with the highest percentage of 56.4, as followed by the third visit with 17.5 percent, fifth or more has 15.0 percent, and the least with 11.1 percent did their fourth or more visit. 
Repeat visitation may relate to customers'/travelers' satisfaction. There are things or reasons that made them go back. It may relate to how the guests being treated during their stay; provide excellent customer service right from the start. Good customer service creates a bond with the staff. It may also relate their satisfaction to good facilities, environment, activities, and the establishment's entire management. They come back again because they feel satisfied with the features or many attributes during the first visits, until the travelers decide to go back repeatedly.

Repeat customers are essential to a business. Staff or greeters are needed to be trained to provide customer service that goes above and beyond; well-versed, friendly, and project positive emotion. Guests should be treated as very important people; guests feel welcomed and appreciated. A good experience leads to positive word-of-mouth referrals, too (Cooper, 2017).

Table 2

Expectations and experiences on attractions in terms of environment

\begin{tabular}{|c|c|c|c|c|c|c|c|c|c|}
\hline \multirow{2}{*}{ Indicators } & \multicolumn{3}{|c|}{ Expectation } & \multicolumn{3}{|c|}{ Experience } & \multicolumn{3}{|c|}{ Overall } \\
\hline & WM & VI & $\mathrm{R}$ & WM & VI & $\mathrm{R}$ & WM & VI & $\mathrm{R}$ \\
\hline 1.Cleanliness & 3.56 & VHE & 2 & 3.46 & $\mathrm{G}$ & 2 & 3.51 & VG & 2 \\
\hline 2. Good weather & 3.44 & $\mathrm{HE}$ & 4 & 3.20 & $\mathrm{G}$ & 8 & 3.32 & $\mathrm{G}$ & 6 \\
\hline 3. historically appealing & 3.45 & $\mathrm{HE}$ & 3 & 3.40 & G & 3 & 3.42 & $\mathrm{G}$ & 3 \\
\hline 4. Modern / visually appealing & 3.28 & $\mathrm{HE}$ & 8 & 3.35 & $\mathrm{G}$ & 6 & 3.31 & $\mathrm{G}$ & 7 \\
\hline 5. With variety of recreational spaces & 3.31 & $\mathrm{HE}$ & 7 & 3.26 & $\mathrm{G}$ & 7 & 3.28 & $\mathrm{G}$ & 8 \\
\hline 6. Pleasantly - built environment & 3.59 & VHE & 1 & 3.59 & VG & 1 & 3.59 & VG & 1 \\
\hline 7. Unspoiled nature & 3.36 & $\mathrm{HE}$ & 5 & 3.36 & $\mathrm{G}$ & 5 & 3.36 & $\mathrm{G}$ & 4.5 \\
\hline 8. Diversity of historical attractions & 3.35 & $\mathrm{HE}$ & 6 & 3.37 & G & 4 & 3.36 & $\mathrm{G}$ & 4.5 \\
\hline Composite Mean & 3.42 & $\mathrm{HE}$ & & 3.37 & $\mathrm{G}$ & & 3.40 & $\mathrm{G}$ & \\
\hline
\end{tabular}

Legend: 3.50 - 4.00 - Very High Expectation/Very Good (VHE/VG); 3.49 - 2.50 - High Expectation/Good (HE/G);

2.49 - 1.50 - Low Expectation/Fair (LE/F); 1.00 - 1.49 -Very Low Expectation/Poor (VLE/P).

Table 2 shows the tourists' feedback on attractions in terms of the environment with a composite mean of 3.42 on expectation and 3.37 on experience, which is verbally interpreted as highly expected and good, respectively. For the overall assessment, getting the highest mean were pleasantly built environment (3.59); cleanliness (3.51) both are verbally interpreted as very good; historically appealing (3.42) with verbal interpretation as good.

Based on the results, the tourists are highly contented and pleasurably experienced with the attraction's pleasing ambiance. For the fact that they have visited the places twice or many times, the respondents are satisfied with the nature-based attributes of the attractions while others have met the purpose of visit in religious sites. The element of building or creating a pleasant environment has an emotional approach extended to the guests. Refreshed and revitalized the feeling from their busy day and exhausting workload. The vacation infused the tiring condition from their routine events (Smith \& Watson, 2012). Meanwhile, the least indicators were good weather (3.32), modern/appealing (3.31), lastly, variety of recreational spaces (3.28). All indicators were verbally interpreted as good.

The actual place may not have the variety of recreational spaces, particularly the religious sites. However, the neighboring town or city may have recreational activities. It is understandable and appropriate that the churches have no such facilities while attractions, mostly offer minimal recreational activities since the places' primary features are usually close to nature. For that matter, the tourists' will not ask much for that on the attractions. Recreation facilities and open space provided should be of high quality, in terms of facilities, layout, and design, which meet the users' needs and aspirations in response to the demand set by the tourism consumers (S. Sinha, 2012a). 
Expectations and experiences of tourists on attractions in Batangas Province

Table 3

Expectations and experiences on attractions in terms of atmosphere

\begin{tabular}{lccccccccc}
\hline \multirow{2}{*}{ Indicators } & \multicolumn{3}{c}{ Expectation } & \multicolumn{3}{c}{ Experience } & \multicolumn{3}{c}{ Overall } \\
\cline { 2 - 9 } & WM & VI & R & WM & VI & R & WM & VI & R \\
\hline 1. Language barriers & 3.62 & VHE & 3 & 3.64 & VG & 2.5 & 3.63 & VG & 3 \\
2. Opportunity to experience local life & 3.34 & HE & 4.5 & 3.30 & $\mathrm{G}$ & 4 & 3.32 & $\mathrm{G}$ & 4 \\
3. Friendly and hospitable local people & 3.65 & VHE & 2 & 3.64 & VG & 2.5 & 3.64 & VG & 2 \\
4. Lively urban atmosphere & 3.34 & HE & 4.5 & 3.28 & $\mathrm{G}$ & 5 & 3.31 & $\mathrm{G}$ & 5 \\
5. Friendliness of the local people & 3.69 & VHE & 1 & 3.68 & VG & 1 & 3.68 & VG & 1 \\
\multicolumn{1}{c}{ Composite Mean } & 3.53 & VHE & & 3.51 & VG & & 3.52 & VG \\
\hline
\end{tabular}

Legend: 3.50 - 4.00 - Very High Expectation/Very Good (VHE/VG); 3.49 - 2.50 - High Expectation/Good (HE/G);

2.49 - 1.50 - Low Expectation/Fair (LE/F); 1.00 - 1.49 -Very Low Expectation/Poor (VLE/P).

Table 3 presents the tourists' feedback on attractions in terms of atmosphere. For expectation, it has a composite mean of 3.53 with a verbal interpretation of very high expectation. For experience, it garnered a weighted mean of 3.51 verbally interpreted as "very good". For overall, friendliness of the local people is the highest indicator with weighted mean of (3.68); while, friendly and hospitable local people (3.64); and language barrier (3.63). All indicators are verbally interpreted as "very good".

In a general perspective, the tourists are happier to find friendly local people. The entire trip is more meaningful as they meet new people. New connections also establish a certain feeling of secured and cared for a while, making new memories far away from home. The staff is composed of the locals who directly contact the visitors and exhibit a unique accent of a Batangueño, expressing a beautiful attitude of being warm and hospitable. The local community can contribute to generating positive publicity and improve reputation. When experienced by the visitors, it gains approval leading to their satisfaction. In addition, in one way or another, it is helping the local people by offering alternative, relatively non-destructive sources of livelihood while benefiting in the existence of the resort's businesses (Tourism Excellence, 2014).

However, in the overall; opportunity to experience local life (3.32); while, lively urban atmosphere (3.31). Both are verbally interpreted as good. In visiting the attractions in Batangas province, the tourist never felt the absence of having a lively urban atmosphere. Near the attractions is the lively urban atmosphere where malls, food chains, and restaurants are just along the highways or neighboring towns. Therefore, they appreciate the presence of urban set-ups in Batangas. In the urban city life, tourists can enjoy movie jamming with their family and friends, others can go to café bistro, malls or do window shopping, and night-life activities: bar or club, resto-bar (MacLellan \& Now, 2017).

\section{Table 4}

Expectations and experiences on attractions in terms of transportation

\begin{tabular}{lccccccccc}
\hline \multirow{2}{*}{ Indicators } & \multicolumn{3}{c}{ Expectation } & \multicolumn{3}{c}{ Experience } & \multicolumn{3}{c}{ Overall } \\
\cline { 2 - 9 } & WM & VI & R & WM & VI & R & WM & VI & R \\
\hline 1. Various types of local transport & 3.47 & HE & 1 & 3.51 & VG & 1 & 3.49 & $\mathrm{G}$ & 1 \\
2. Safe transportation to and from places & 3.37 & HE & 5 & 3.33 & $\mathrm{G}$ & 3 & 3.35 & $\mathrm{G}$ & 4 \\
3. Good condition of roads and highways & 3.40 & $\mathrm{HE}$ & 3 & 3.06 & $\mathrm{G}$ & 7.5 & 3.23 & $\mathrm{G}$ & 6 \\
4. Reasonable fares & 3.38 & $\mathrm{HE}$ & 4 & 3.36 & $\mathrm{G}$ & 2 & 3.37 & $\mathrm{G}$ & 3 \\
5. Easily reached destination & 3.27 & $\mathrm{HE}$ & 7 & 3.12 & $\mathrm{G}$ & 6 & 3.19 & $\mathrm{G}$ & 7 \\
6. Convenience of the local transportation & 3.35 & $\mathrm{HE}$ & 6 & 3.30 & $\mathrm{G}$ & 5 & 3.33 & $\mathrm{G}$ & 5 \\
7. Short travel time & 3.20 & $\mathrm{HE}$ & 8 & 3.06 & $\mathrm{G}$ & 7.5 & 3.13 & $\mathrm{G}$ & 8 \\
8. Availability of transportation facilities & 3.44 & $\mathrm{HE}$ & 2 & 3.31 & $\mathrm{G}$ & 4 & 3.38 & $\mathrm{G}$ & 2 \\
\multicolumn{1}{c}{ Composite Mean } & 3.36 & $\mathrm{HE}$ & & 3.26 & $\mathrm{G}$ & & 3.31 & $\mathrm{G}$ & \\
\hline
\end{tabular}

Legend: 3.50 - 4.00 - Very High Expectation/Very Good (VHE/VG); 3.49 - 2.50 - High Expectation/Good (HE/G);

2.49 - 1.50 - Low Expectation/Fair (LE/F); 1.00 - 1.49 -Very Low Expectation/Poor (VLE/P).

Table 4 presents the expectations and experiences on attractions in Batangas Province in terms of transportation. For expectation, it obtained a composite mean of 3.36 verbally interpreted with high expectation. For experience, it has a composite mean of 3.26 and overall got 3.31; both were verbally interpreted as good. The 
overall results revealed the higher indicators were that various types of local transports (3.49), availability of transportation facilities (3.38), and reasonable fares (3.37). All these indicators are verbally interpreted as good.

Based on the results, various types of local transports are highly expected and experienced as it leads consistently on both expectation and experience. Since the tourists traveled twice or often in Batangas, they are all aware of the availability and accessibility of the province's different types of local transport. Thus, it scored most in the overall presentation. In Batangas, local transports are always available at any time of the day, even the transportation going to and from Manila. National roads are accessible to enter or exit to or from neighboring provinces: Laguna, Quezon, Lucena, Cavite, and Manila. At the same time, Batangas port is viable to Mindoro, Masbate, or Katiklan (Batangas, all here, so near, 2015).

Meanwhile, the least indicators are good conditions of roads and highways (3.23), easily reached destination (3.19), and short travel time (3.13). All respondents agreed that they are good. The tourists agreed that short travel time going to attractions is possible; however, traffic or narrow facilities creates an effect on travel time. Also, the entry point and exits are via sea travel that took it a long journey of travel. Batangas is near in Manila by two hours' travel. Motorists travel via Star Toll and other points of entries and exits in Batangas. CALABARZON's connecting roads are also available via South Luzon Expressway (Batangas, all here, so near, 2013).

Table 5

Expectations and experiences on attractions in terms of tourism services

\begin{tabular}{|c|c|c|c|c|c|c|c|c|c|}
\hline \multirow{2}{*}{ Indicators } & \multicolumn{3}{|c|}{ Expectation } & \multicolumn{3}{|c|}{ Experience } & \multicolumn{3}{|c|}{ Overall } \\
\hline & WM & VI & $\mathrm{R}$ & WM & VI & $\mathrm{R}$ & WM & $\mathrm{VI}$ & $\mathrm{R}$ \\
\hline $\begin{array}{l}\text { 1. Availability of tourist information (brochures, } \\
\text { tarpaulins, flyers, etc.) }\end{array}$ & 3.28 & $\mathrm{HE}$ & 4 & 3.05 & $\mathrm{G}$ & 4 & 3.17 & G & 4 \\
\hline 2. Availability of tourist attraction signage & 3.38 & $\mathrm{HE}$ & 3 & 3.30 & $\mathrm{G}$ & 3 & 3.34 & $\mathrm{G}$ & 3 \\
\hline $\begin{array}{l}\text { 3. Availability of tourist assistance (guides \& } \\
\text { other frontlines }\end{array}$ & 3.25 & $\mathrm{HE}$ & 5 & 2.95 & $\mathrm{G}$ & 5 & 3.10 & $\mathrm{G}$ & 5 \\
\hline 4. Reasonable fees (environmental \& entrance) & 3.41 & $\mathrm{HE}$ & 2 & 3.33 & $\mathrm{G}$ & 2 & 3.37 & $\mathrm{G}$ & 2 \\
\hline 5. Personal safety and security & 3.56 & VHE & 1 & 3.46 & $\mathrm{G}$ & 1 & 3.51 & VG & 1 \\
\hline Composite Mean & 3.38 & $\mathrm{HE}$ & & 3.22 & $\mathrm{G}$ & & 3.30 & $\mathrm{G}$ & \\
\hline
\end{tabular}

Legend: 3.50 - 4.00 - Very High Expectation/Very Good (VHE/VG); 3.49 - 2.50 - High Expectation/Good (HE/G);

2.49 - 1.50 - Low Expectation/Fair (LE/F); 1.00 - 1.49 -Very Low Expectation/Poor (VLE/P).

Table 5 shows the expectations and experiences on attractions in terms of tourism services. Expectations garnered a composite mean of 3.38 and verbally interpreted with high expectation, while for experience 3.22 composite mean and overall (3.30). Overall have tourist services are perceived good. For the overall, the top enumerated indicators were personal safety and security (3.51); verbally interpreted as very good. Meanwhile, reasonable fees (3.37) and availability of tourist attraction signage (3.34), both indicators are verbally interpreted as good. In all cases or situations, people are after their personal safety and security. Most tourists are so concerned about it, most especially if they are with their family, relatives, and friends. When people are engaged in traveling, life is always at risk when engaging in different activities while visiting the attractions.

Factors on safety while traveling may refer to individual circumstances, areas of travel, and personal perceptions. Different people exhibit different levels of risk tolerance. Nevertheless, everyone must pay attention to their surroundings to secure personal safety and security (Dyment, 2017). Moreover, the least indicators are the availability of tourist information (brochures, tarpaulins, flyers, etc.) (3.17) and the availability of tourist assistance (3.10); both are verbally interpreted as good. Since the majority of the respondents are local tourists, they are confident that they can visit new and different places on their own without asking for any tourist assistance. However, foreign visitors are expecting the visibility and availability of tourist assistance when they needed to. Tourist assistance is vital in the tourism industry in providing better access to attractions or destinations. It made the travel valuable and meaningful because the tourists are well guided and well provided with information (ecotourism Batangas, 2010). 
Expectations and experiences of tourists on attractions in Batangas Province

Table 6

Expectations and experiences on attractions in terms of tourist activities

\begin{tabular}{|c|c|c|c|c|c|c|c|c|c|}
\hline \multirow{2}{*}{ Indicators } & \multicolumn{3}{|c|}{ Expectation } & \multicolumn{3}{|c|}{ Experience } & \multicolumn{3}{|c|}{ Overall } \\
\hline & WM & VI & $\mathrm{R}$ & WM & VI & $\mathrm{R}$ & WM & VI & $\mathrm{R}$ \\
\hline $\begin{array}{l}\text { 1. Variety of adventurous, challenging, and } \\
\text { exciting outdoor trips (hiking, camping, wall } \\
\text { climbing, etc.) }\end{array}$ & 2.48 & LE & 5 & 2.34 & $\mathrm{~F}$ & 5 & 2.41 & $\mathrm{~F}$ & 5 \\
\hline 2. Opportunity to be close to nature & 3.20 & $\mathrm{HE}$ & 2 & 3.26 & $\mathrm{G}$ & 2 & 3.23 & $\mathrm{G}$ & 2 \\
\hline 3. Opportunity to join recreational activities & 2.99 & $\mathrm{HE}$ & 3.5 & 3.03 & $\mathrm{G}$ & 3 & 3.01 & G & 3 \\
\hline 4. Availability of cultural and other events & 2.99 & $\mathrm{HE}$ & 3.5 & 3.00 & $\mathrm{G}$ & 4 & 2.99 & $\mathrm{G}$ & 4 \\
\hline 5. Participate in religious activities & 3.55 & VHE & 1 & 3.58 & VG & 1 & 3.56 & VG & 1 \\
\hline Composite Mean & 3.04 & $\mathrm{HE}$ & & 3.04 & $\mathrm{G}$ & & 3.04 & $\mathrm{G}$ & \\
\hline
\end{tabular}

Legend: 3.50 - 4.00 - Very High Expectation/Very Good (VHE/VG); 3.49 - 2.50 - High Expectation/Good (HE/G);

2.49 - 1.50 - Low Expectation/Fair (LE/F); 1.00 - 1.49 -Very Low Expectation/Poor (VLE/P).

Table 6 presents the tourists' expectations and experiences on attraction in terms of tourist activities. The expectation and experience and overall got the same composite mean of 3.04; however, they differ in verbal interpretation. Based on the findings to participate in religious activities is highly anticipated by the respondents but when they experienced it is less than with their expectation. Overall, the topmost indicators were the opportunity to participate in religious activities (3.56), which is has a verbal interpretation of very good. While the opportunity of tourists to be close to nature (3.23) and the opportunity to join recreational activities (3.01) has the same verbal interpretation as good.

Most of the respondents traveled to Batangas to participate in various religious activities or attend to pilgrimages. The result figured out that the respondents' primary purpose of travel is associated with their spiritual commitment or devotions. Thus, Padre Pio National Shrine placed the top one most visited attraction in Batangas Province. Religious sites are inspiring natural places, connected to God, historical places where miracles or visions were reported or maybe buildings consecrated for worship or ritual visited by the travelers (Sacred Destinations, 2017).

The two remaining least indicators are the availability of cultural and other events (2.99) interpreted verbally as good while, variety of adventurous, challenging, and exciting outdoor trips such as hiking, camping, and wall climbing (2.41) is verbally interpreted as fair. Since the visited attraction is associated with cultural and heritage site; having Adventurous and challenging events, as well as to engage in exciting outdoor trips is not part of assumed activities. Visiting historical site basically offers sightseeing activities. Unless the site is located at the top of the mountain trekking is added attraction or tourist activity. But in the case of cultural and heritage site in CALABARZON that most identified in the area museums therefore, activity are limited to browsing artifact, looking at the murals, viewing the exhibit or displays of historical remains.

Some resorts' various adventure activities include paddle boat, kayaking, diving, and few to mention. Others are forms of trampoline, bungee jumping, rappelling, rock climbing wall, and other relevant sports climbing (S. Sinha, 2012b).

Table 7

Summary table of the expectations and experiences of tourists on attractions

\begin{tabular}{|c|c|c|c|c|}
\hline \multicolumn{2}{|c|}{ Indicators } & WM & VI & Rank \\
\hline 1. Environment & & 3.40 & $\mathrm{G}$ & 2 \\
\hline 2. Atmosphere & & 3.52 & VG & 1 \\
\hline 3. Transportation & & 3.31 & $\mathrm{G}$ & 3 \\
\hline 4. Tourism Services & & 3.30 & G & 4 \\
\hline 5. Tourist Activities & & 3.04 & G & 5 \\
\hline & Overall Composite Mean & 3.31 & G & \\
\hline
\end{tabular}

Legend: 3.50 - 4.00 - Very High Expectation/Very Good (VHE/VG); 3.49 - 2.50 - High Expectation/Good (HE/G);

2.49 - 1.50 - Low Expectation/Fair (LE/F); 1.00 - 1.49 -Very Low Expectation/Poor (VLE/P). 
Table 7 displays the summary of the expectations and experiences on attractions with an overall composite mean of 3.31 verbally interpreted as good. As arranged accordingly, the highest was atmosphere (3.52), verbally interpreted as very good; Environment (3.40) and transportation (3.31), which are both interpreted as good.

The atmosphere or the people who surrounded the tourists during their travel time have a great impact on their experiences. However, there is a greater expectation on that aspect. From the staff/management and the local people in the transit, routes are all significant in giving tourists opportunities to have a meaningful stay in the attractions. The inter-relationships on economic and social benefits tourism uplift the local communities. Thus, enhancing local amenities will help attract visitors also make the host community a great place to live. This investment also benefits industries other than tourism (Tourism Excellence, 2014).

The two remaining variables are tourism services and tourism activities (3.30); and (3.04) respectively, with the same verbal interpretation rated as good. Since the tourists are not first-timer, they are aware of different tourist activities in the attractions. Whatever activities they may encounter in the attractions in Batangas is acceptable to them. Based on their profile, they have visited the place for several times. Giving more importance to the tourism activities generates more tourists to come. Creating tourist influx in a particular destination will generate income through job employment, build business opportunity thus, will contribute to the economic growth of the resort's businesses, residents, and local government (V. Sinha, 2012).

\section{Table 8}

Relationship between expectations and experiences on attractions in Batangas Province

\begin{tabular}{ccccc}
\hline \multicolumn{1}{c}{ Factors } & $r$ value & $p$ value & Decision & Interpretation \\
\hline Experience vs. Expectation & .478 & .000 & Rejected & Significant \\
\hline Note. Significant at $p$-value $<0.05$. & & &
\end{tabular}

Table 8 presents the relationship between the experience and expectation and tourists' feedback on attractions in Batangas province. The computed $r$-value of .478 indicates a moderately low positive correlation, and the resulting $p$-value of .000 is less than the .05 level of significance. Thus, the null hypothesis on the relationship between experience and expectation of tourists' feedback on tourist attractions is rejected. Therefore, there is a significant relationship between expectation and experience and tourist feedback on attractions in Batangas Province. From the given variables: the respondents, fortunately, experienced their expectations. However, some expectations are the least experienced. For instance, modern/visually appealing in the environment have the least expectation but experienced as good. Tourists are expecting more on the side of photographic appealing and less on the attraction's modern features, since they are aware that the actual location of the place is in the rural or geographically in the province.

The visual appeal has an important role in the preference of the tourists. It will complement the entire look of the building, the functional spaces found within, also creating a connection to the motion (Page, 2011). Furthermore, the respondents are expecting to have good weather but least experienced during the visit. Weather is an implication to make or break the entire flow of the travel. It has a great impact on the travel plan. Change in the plan may occur immediately. Likewise, it creates disappointment on both parties between the organizers, tourist service providers, and the tourists.

Changes in travel plans due to weather conditions have some consequences to undertake in transforming the tourists' experiences still meaningful and memorable. The weather condition affects business operations and income. It has a chain reaction on the tourist plan or travel schedule and transfers. For some cases, delayed flight schedule and rebooking, rescheduling of the travel or worst, no show from the guests or cancellation of reservation/flights (Smith \& Watson, 2011). Finally, in transportation, the indicator with the highest expectation is the good road and highways condition but got an assessment as good only on the part of the experience.

Road facilities are one of the considerations looking at by the tourists. People hate traffic for this lessens the time spent on their holidays. Road condition is vital in reaching the attractions at a specified time. Road facilities

20 Consortia Academia Publishing (A partner of Network of Professional Researchers and Educators) 
and their condition should be maintained or improved. There is a for better utilization for whatever purpose it may serve in the community, the consumers, and tourism service providers. The destination is accessible if roads are available (Penhall Company, 2014).

Table 9

Proposed action plan based on the result of the study

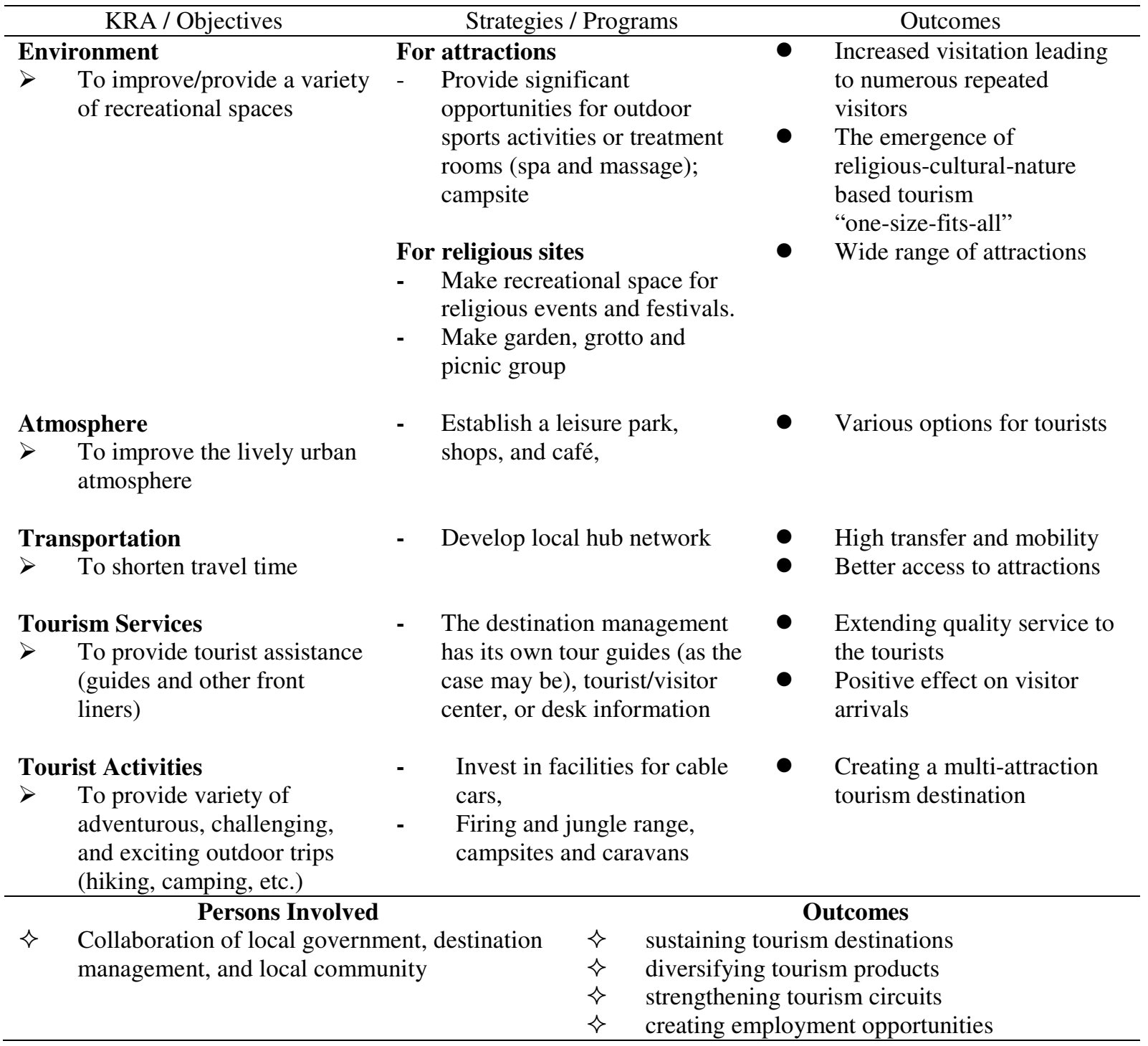

\section{Conclusion}

The majority of the respondents of attractions is second-timers and has visited the place many times. The expectations and experiences in attractions are parallel in all given instances on the pleasantly built environment, friendliness of the local people, various local transport types, personal safety and security, and the opportunity to participate in religious activities. There is a significant relationship between expectation and experience on attractions in Batangas province. There is high satisfaction in the aspect of atmosphere in the attraction. The researcher proposes an action for the innovative improvement of Batangas province's tourist destination.

The researcher recommends the following: The management of attraction may focus on developing new facilities and improving the existing tourist activities. The management of attractions may invest in developing or acquiring new facilities in providing new trends in tourist activities. The management of attraction may utilize the proposed action plan for innovative improvement. The future researcher may conduct similar research study 
Apritado, J. M., \& Borbon, N. M. D.

using a different set of variables.

\section{References}

Batangas. All Here. So Near. (2013). Retrieved from https://www.batangasallheresonear.com

Becken, S., \& Scott, D., (2010). Adapting to climate change and climate policy: Progress, problems and potentials. Journal of Sustainable Tourism, 18(3), 283-295. https://doi.org/10.1080/09669581003668540

Canadian Tourism Human Resource Council. (n.d.). ecotourism-ala-Batangas. Retrieved from https://www.tc.gov.yk.ca

Coffey, H. (2017). Travel expectations vs reality: Photos reveal what tourist attractions are really like. Retrieved from https://www.express.co.uk/travel/articles/761323/tourist-attractions-real-life-photos

Cooper, C. (2016). Essentials of tourism. Sage Publications.

Dyment, D. (2017). Personal safety and security. Retrieved from http://www.onebag.com

Ecotourism Batangas. (2010). Retrieved from https://ecotourismbatangas.wordpress.com

Kucharsky, D., (2015). Measuring the gap between consumer expectations and experiences. Retrieved from http://marketingmag.ca/brands/measuring-the-gap-between-consumer-expectations-and-experiences-15 $\underline{9257 /}$

MacLellan, J., \& Burnaby, N., (2017). Lively city: Luminescence II, urban art and more. http://www.burnabynow.com/entertainment/lively-city-luminescence-ii-urban-art-and-more-1.10820342

Page, S. (2011). Tourism management: An introduction. Routledge. https://doi.org/10.4324/9780080879369

Penhall Company. (2014). Penhall company to expand operations in Texas. Retrieved from http://www.prnewswire.com

Quach, P. G. (2013). Examining international tourists "Satisfaction with Hanoi tourism” [Thesis]. EMACIM Studies Spring. Retrieved from http://lauda.ulapland.fi

Rodrigo. (2012). Research methodology on hospitality and tourism. Retrieved from https://writepass.com/journal/2012/12/research-methods-for-hospitality-and-tourism-managers/

Sacred Destination. (2017). Welcome to sacred destinations. Retrieve from http://www.sacred-destinations.com

Sinha, S. (2012a). International tourism and sustainable development. S. K. Mehra for Random Publications.

Sinha, S. (2012b). Modern hospitality and tourism management. Random Publications.

Sinha, V. (2012). Tourism planning and management. Random Publications.

Smith, K., \& Watson, S. (2011). Tourism and demography. Goodfellow Publishers.

Stange, J., \& Brown, D. (2010). Tourism destination management achieving sustainable and competitive results. Retrieved from http://www.usaid.gov

Tourism Education. (2016). Tourism industry; nature and characteristics. Retrieved from http://freetourismedu.blogspot.com

Tourism Excellence. (2014). Working with local communities. Retrieved from http://www.tourismexcellence.com.au

Wang, Y. (2016). More important than ever: Measuring tourist satisfaction. Retrieved from https://www.griffith.edu.au 